\title{
Notes on the vocalizations of Chestnut-capped Brush-finch (Arremon brunneinucha)
}

Peter Boesman

In the following we briefly analyze and compare voice of several races of Chestnut-capped Brush-finch (Arremon brunneinucha). We also try to quantify the extent of any vocal differences using the criteria proposed by Tobias et al. (2010), as a support for taxonomic review. We have made use of sound recordings available on-line from Xeno Canto (XC).

Our main interest is to compare voice of race apertus with other races, as the former has been suggested to represent a distinct species (Navarro-Sigüenza et al. 2004).

We have found only a single recording of song for race apertus:

apertus

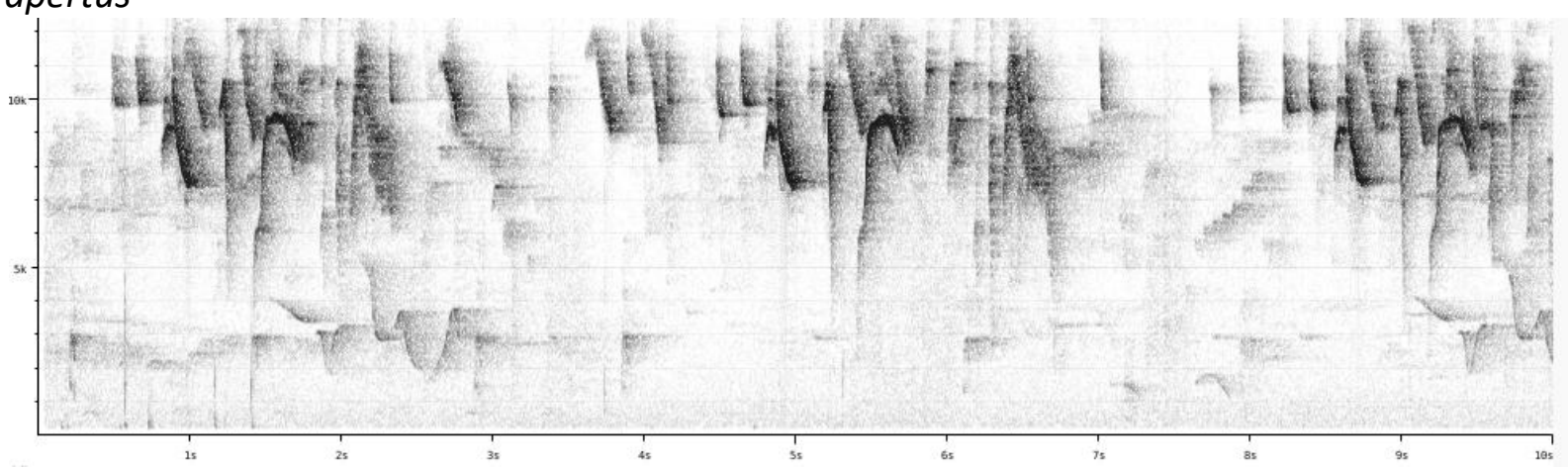

to be compared with geographically closest race brunneinucha:

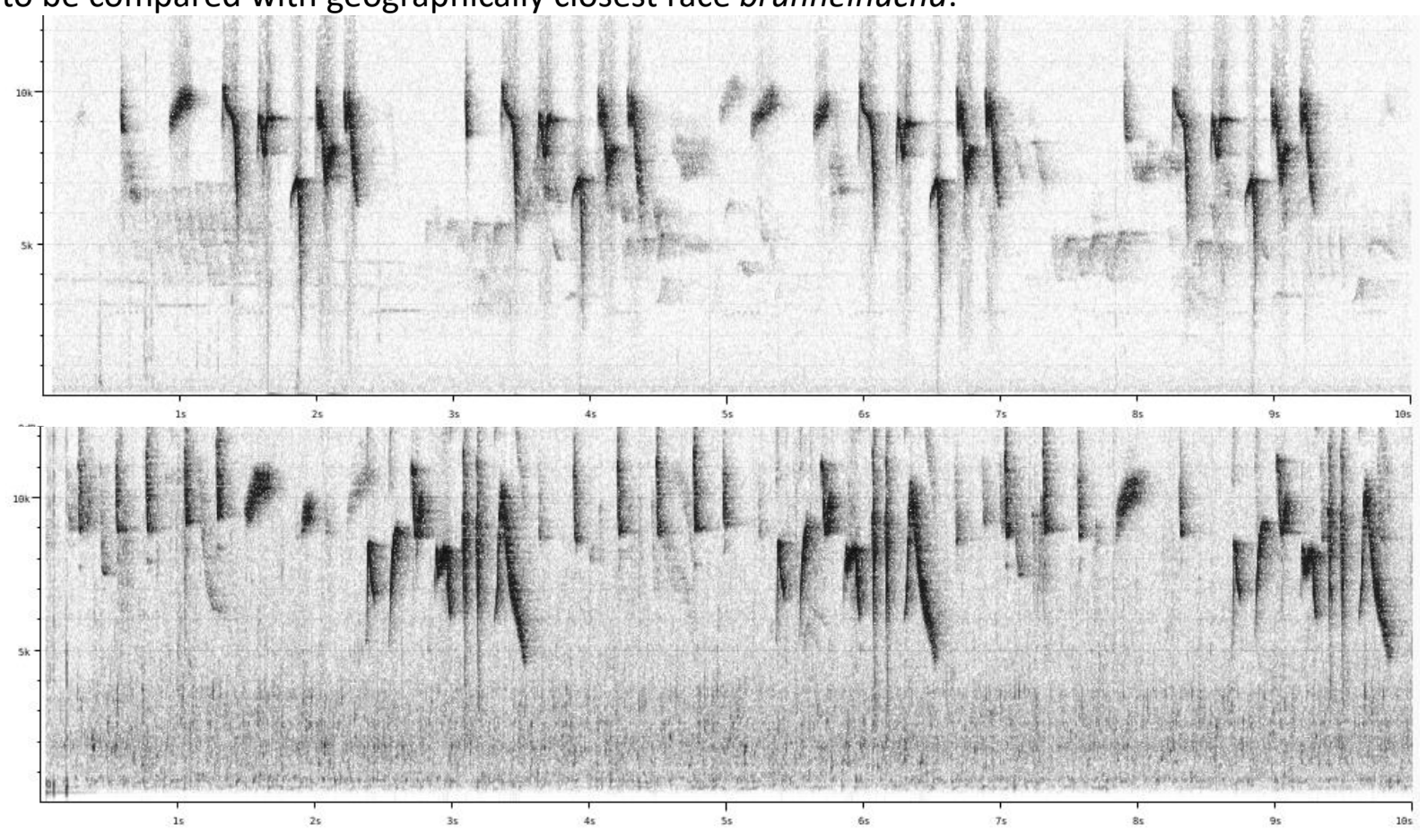


HANDBOOK OF THE

BIRDAPIUE WORLD ORNITHOLOGICAL NOTES

Hone

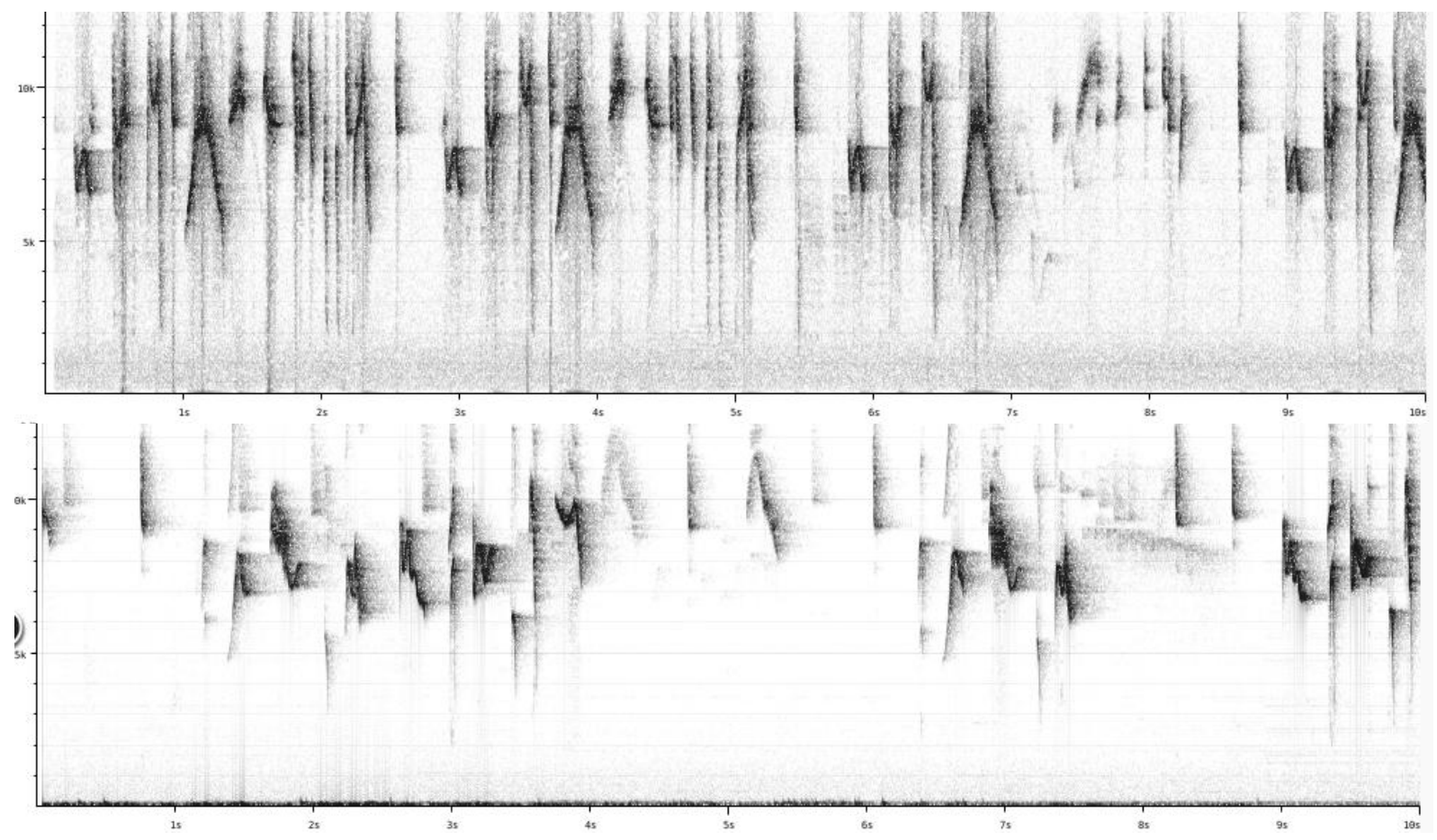

There seem to be no obvious differences in song. As a matter of fact, differences of Mexican races vs other races are more outspoken, e.g.:

Costa Rica/Panama highlands (elsae) : shorter, simpler phrases with narrower freq. range

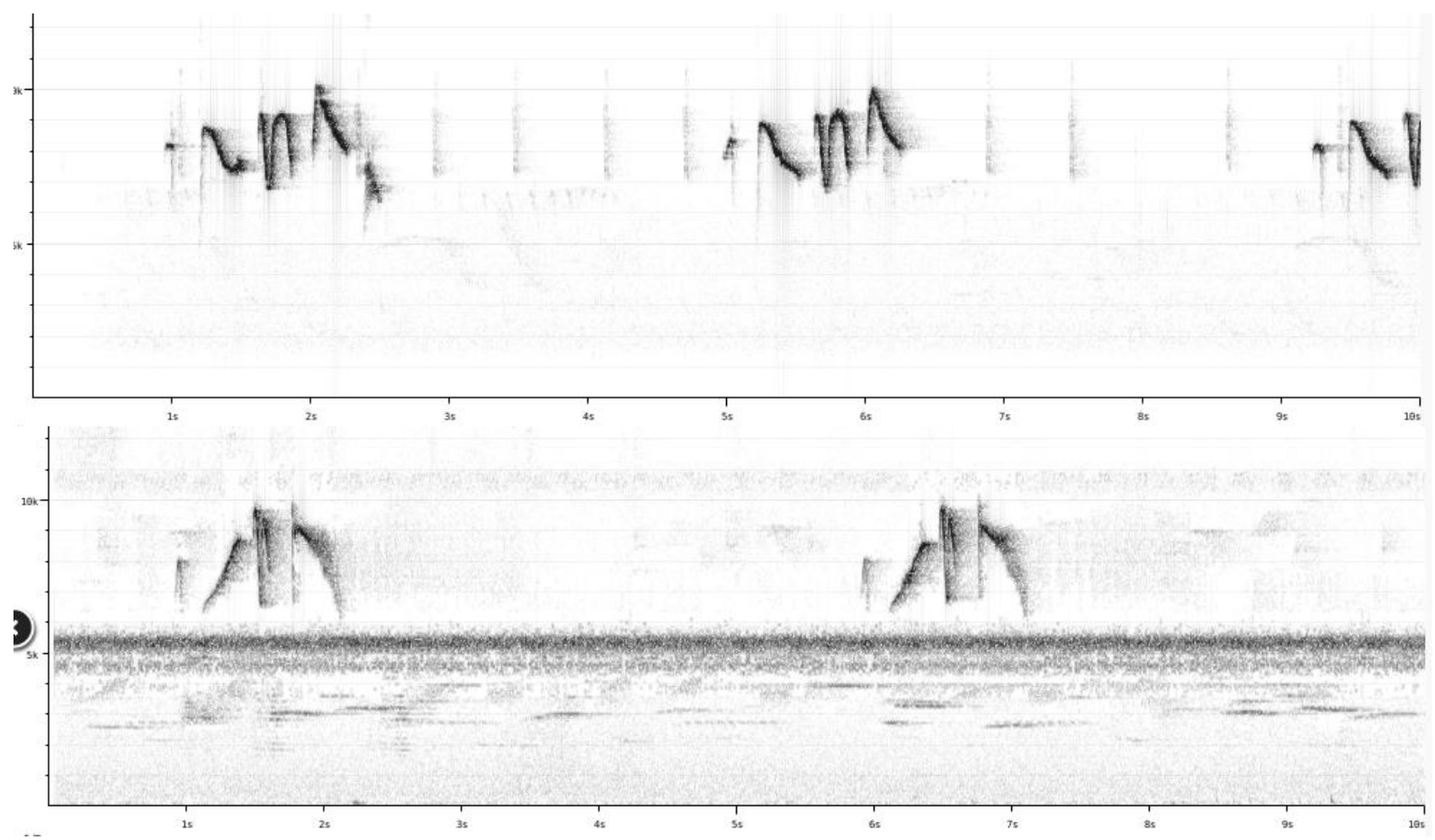

2 


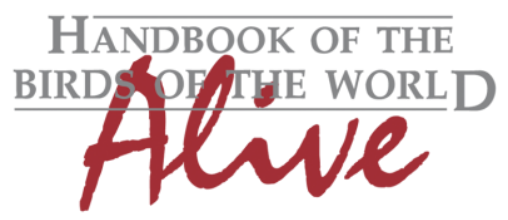

\section{ORNITHOLOGICAL NOTES}

In South America, there is quite some variation within wide-spread race frontalis, but notes on average cover a narrower frequency range :

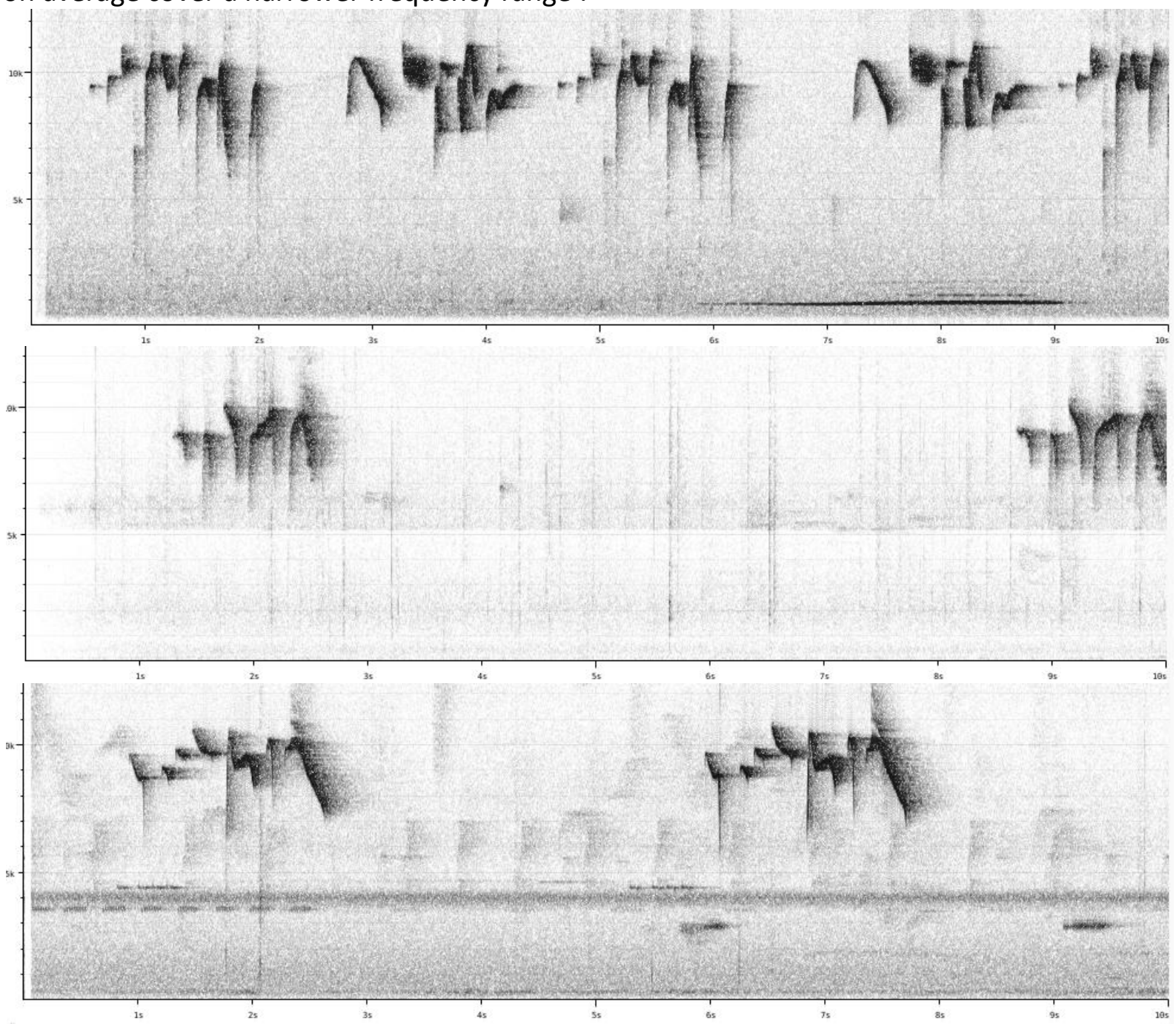

We can thus conclude that song of race apertus is not markedly different from its neighboring race, but at the other hand there seems to be a slight change in voice south of the isthmus of Tehuantepec, with song covering a narrower frequency range and note shapes somewhat less steeply changing pitch (lacking the multiple 'vertical lines' on a sonogram). A more detailed analysis would be required to have a better quantification of this vocal change.

This note was finalized on 25th May 2016, using sound recordings available on-line at that moment. We would like to thank in particular the many sound recordists who placed their recordings for this species on XC. 


\section{References}

Navarro-Sigüenza, A.G. \& Peterson, A.T. (2004). An alternative species taxonomy of the birds of Mexico. Biota Neotropica 4(2): 1-32.

Tobias, J.A., Seddon, N., Spottiswoode, C.N., Pilgrim, J.D., Fishpool, L.D.C. \& Collar, N.J. (2010). Quantitative criteria for species delimitation. Ibis 152(4): 724-746.

\section{Recommended citation}

Boesman, P. (2016). Notes on the vocalizations of Chestnut-capped Brush-finch (Arremon brunneinucha). HBW Alive Ornithological Note 360. In: Handbook of the Birds of the World Alive. Lynx Edicions, Barcelona. (retrieved from http://www.hbw.com/node/1252903 on 28 October 2016). 